\title{
Cara Meningkatkan Sikap dan Karakteristik Kepemimpinan (Leadership) Dalam Berorganisasi Bagi Para Pemuda Karang Taruna Banyu Urip, Surabaya
}

\author{
${ }^{1}$ Mohamad Yusak Anshori, ${ }^{2}$ Riyan Sisiawan Putra, ${ }^{3}$ Inayatus Sholikhah, ${ }^{4}$ Ravica Ulya Arifin \\ 1,2,3,4 Universitas Nahdlatul Ulama Surabaya
}

\begin{abstract}
Alamat Surat
Email: Yusak.anshori@gmail.com, riyan_sisiawan@unusa.ac.id*, inayatussh2@gmail.com, ravicaulya99@gmail.com
\end{abstract}

Article History:

Diajukan: 20 Januari 2021; Direvisi: 2 Februari 2021; Accepted: 5 Februari 2021

\begin{abstract}
ABSTRAK
Kegiatan pengabdian kepada masyarakat ini dilaksanakan di Balai RW Banyuurip Surabaya dan peserta kegiatan pengabdian kepada masyarakat ini dari Para pemuda karang taruna Surabaya. Pemuda karang taruna ini kurang lebihg berjumlah 50 orang. Melihat begitu pentingnya sikap leadership bagi para pemuda saat ini menjadi hal yang perlu diimplementasikan pula kepada para karangtaruna Banyuurip agar tercapainya tujuan bersama dengan diadakannya peningkatan kesadaran mengenai kepemimpinan untuk menciptakan organisasi yang efektif bagi para pemuda karangtaruna.

Metode pelaksanaan kegiatan pengabdian kepada masyarakat ini terdiri dari tiga tahap. Pertama tahap pesiapan melalui pra-survei, pembentukan tim, pembuatan proposal, koordinasi tim dengan mitra, dan persiapan bahan untuk kegiatan bahan pengabdian kepada masyarakat. Tahap kedua yaitu tahap pelaksanaan program berupa sosialisasi. Sosialisasi dilakukan melalui pemaparan materi, tanya jawab dan diskusi. Dan tahap terakhir adalah pelaporan hasil kegiatan pengabdian kepada masyarakat.
\end{abstract}

Kata kunci: Kepemimpinan, Organisasi, Motivasi

ABSTRACT

This community service activity was carried out at the Banyuurip Surabaya $R W$ Hall and the participants of this community service activity were from the youth of Surabaya youth organization. This youth youth organization numbered approximately 50 people. Seeing the importance of leadership attitudes for young people today is something that needs to be implemented also for Banyuurip youth organizations in order to achieve common goals by raising awareness about leadership to create an effective organization for youth Karangtaruna.

This method of implementing community service activities consists of three stages. The first is the preparation stage through pre-survey, team formation, proposal development, team coordination with partners, and preparation of materials for community service activities. The second stage is the program implementation stage in the form of socialization. Socialization is carried out through material presentation, question and answer and discussion. And the last stage is the reporting of the results of community service activities.

Keywords: Leadership, Organization, Motivation

\section{PENDAHULUAN}

Pengabdian Masyarakat yang akan Tim laksanakan berlokasi di balai RW Banyuurip, Surabaya dan untuk peserta kegiatan pengabdian masyarakat ini berasal dari para pemuda karangtaruna Banyuurip, Surabaya.Balai RW Banyuurip berlokasi di Kecamatan Sawahan, Surabaya Utara. 
Pemuda karangtaruna Banyuurip kurang lebih berjumlah 50 orang dengan latar belakang dan status yang berbeda-beda, ada yang sudah bekerja, kuliah, berbisnis, dan lain sebagainya. Melihat dari pengalaman yang pernah mereka alami sebagian besar dahulu mereka pernah bergelut di keorganisasian sebelum mereka turut aktif sebagai anggota karangtaruna. Dari pengalaman ikut keorganisasian saat sekolah dan kuliah, mereka turut mengimplementasikan beberapa kegiatan di karangtaruna sebagai kontribusi anggota organisasi

Dengan berbagai pengembangan, pemuda karangtaruna Banyuurip diarahkan untuk menjadi pemuda yang bisa menjadi leader yang aktif dan mampu menjadi pemimpin ataupun berkontribusi dalam sebuah organisasi. Sebagai seorang agen of change, para pemuda karangtaruna Banyuurip memiliki sebuah tuntutan untuk terus memberikan sebuah solusi bagi semua masyarakat. Melihat begitu pentingnya sikap leadership bagi para pemuda saat ini menjadi hal yang perlu diimplementasikan pula kepada para karangtaruna Banyuurip agar tercapainya tujuan bersama dengan diadakannya peningkatan kesadaran mengenai kepemimpinan untuk menciptakan organisasi yang efektif bagi para pemuda karangtaruna. Dengan berjalannya organisasi yang aktif dan efektif, para pemuda karangtaruna Banyuurip dapat menjadi harapan besar untuk memajukan daerah Banyuurip, Surabaya

Pentingnya kepemimpinan dalam organisasi menurut Suranta (2002) dikarenakan pemimpin memiliki peran strategis dalam usaha mencapai tujuan organisasi sesuai visi dan misi organisasi. Menurut Jack Welch dalam Slater (2001:33), pemimpin adalah orang yang memberikan inspirasi dengan visi yang jelas mengenai bagaimana sesuatu dapat dikerjakan dengan cara yang lebih baik. Robbins (2003:40) menyatakan bahwa kepemimpinan (leadership) adalah kemampuan untuk mempengaruhi suatu kelompok kearah tercapainya tujuan. Sementara Stoner (1996:161) menyatakan bahwa kepemimpinan adalah proses mengarahkan dan mempengaruhi aktifitas yang berkaitan dengan pekerjaan dari anggota kelompok. Kepemimpinan (leadership)mempunyai peranan yang sangat penting dalam pencapaian keberhasilan sebuah organisasi dikarenakan mampu mempengaruhi kinerja dari organisasi tersebut. Oleh karena itu perlu dibentuknya sikap dan karakteristik leadership bagi para pemuda. Menurut Atmadja (2012: 18), karakter kepemimpinan adalah kualitas personal dari seorang pemimpin yang terbentuk melalui akumulasi tindakan-tindakan yang mengacu kepada nilai-nilai moralitas dan etika (moral / ethical values) yang diyakini oleh seorang pemimpin. Karakter tidak cukup hanya dibentuk melalui ucapan-ucapan, tetapi juga melalui pikiran dan tindakan riil (characters is values in action). Pemimpin yang memiliki kualitas karakter (character qualities) yang baik dan kuat adalah pemimpin yang berpikir, bersikap, dan bertindak mengikuti nilai-nilai inti universal (universal core values) yang baik seperti kejujuran (honesty), keterpercayaan (trustworthiness), tanggungjawab (responsibility), kepedulian kepada negara (citizenship), dan sebagainya.

Karakter dicerminkan oleh perilaku dan tindakan yang konsisten yang dilakukan seseorang, tak peduli situasi apa yang dia hadapi. Dalam situasi apapun, pemimpin yang berkarakter akan selalu mempraktikan nilai-nilai yang ia yakini. Menurut Atmadja (2012:26) ada lima karakter kepemimpinan yang kemudian dikelompokkan dalam tiga tingkatan sebagai berikut:

1. Dimensi Spiritual (spiritual dimension) atau disebut sebagai Karakter Moral (moral character) terdiri dari Selfless (Ikhlas) dan Honesty (Kejujuran)

2. Dimensi Emosional (emotional dimension) atau disebut sebagai Karakter Sosial (social character) terdiri dari Respect (menghargai) dan Empathy (memahami).

3. Dimensi Rasional (rational dimension) atau disebut sebagai Karakter Kinerja (performance character) yaitu pursuit of exellence (sikap mental untuk mencapai hasil yang terbaik)

Peserta membutuhkan pemahaman mengenai kepemimpinan (leadership) bagaimana cara untuk menciptakan sikap leadership dalam berorganisasi. Pengabdian masyarakat yang akan dilakukan berfokus mengenai sikap kepemimpinan dengan tujuan untuk menumbuhkan jiwa leadersejak muda dan supaya peserta bisa mengatur dan mengelola organisasi dengan baik. Sikap kepemimpinan akan sangat berpengaruh juga terhadap manajemen sumber daya manusia. Sumber daya manusia merupakan aset yang sangat penting dikarenakan apabila sumber daya manusia dalam 
sebuah organisasi ini bagus, maka akan dapat menguntungkan organisasi juga dan lebih muda dalam mencapai tujuan bersama, (Riyan Sisiawan:2013)

Berdasarkan analisis situasi yang telah dipaparkan diatas, dapat disimpulkan beberapa permasalah mitra. Permasalahan tersebut adalah sebagai berikut:

1. Kurangnya pemahaman tentang Kepemimpinan dan pentingnya mempunyai sikap dan karakteristik leadership bagi para karangtaruna Banyuurip, Surabaya.

2. Kurangnya motivasi dalam berorganisasi, akan tetapi para pemuda berkeinginan untuk berkontribusi dalam membangun organisasi yang aktif dan solid.

\section{METODE PELAKSANAAN}

Untuk merealisasikan program ini maka upaya yang dilaksanakan ada 7 tahap mulai daripersiapan sampai tahap pelaksanaan program yaitu antara lain:

1. Mengidentifikasi permasalahan dan kebutuhan mitra

2. Pembentukan Tim: Pembentukan tim disesuaikan dengan jenis kepakaran untuk menyelesaikan permasalahan mitra

3. Pembuatan proposal untuk menawarkan solusi permasalahan dan anggaran dana dalam pelaksanaan kegiatan pengabdian masyarakat

4. Perencanaan pelaksanaan program secara konseptual, operasional dan disesuaikan dengan job desc nya masing-masing anatara Tim dan Mitra.

5. Persiapan bahan Pengabdian Masyarakat: Pembuatan materi kegiatan

6. Sosialisasi mengenai usaha ekonomi kreatif (creativepreneur)

7. Penyusunan laporan dilakukan sebagai bentuk pertanggung jawaban atas pelaksanaan program untuk kemudian di publikasikan.

\section{HASIL KEGIATAN}

Hasil dari proses pengabdian masyarakat yaitu, dalam pelaksanaan program kegiatan meliputi:

1. Sosialisasi

Program pengabdian masyarakat dilaksanakan dalam bentuk sosialisai kepada mitra karangtaruna Banyu urip Surabaya.Sosialisasi tersebut berupa pemaparan materi kepada para Karangtaruna Banyuurip Surabaya terkait menumbuhkan jiwa kepemimpinan (leadership).Materi yang sudah disampaikan diharapkan dapat memberikan peningkatan pengetahuan dan pemahaman supaya bisa di terapkan apabila para pemuda terjun dalam berorganisasi.

2. Diskusi

Setelah materi selesai di sampiakan, dilanjutkan sesi diskusi dengan tanya jawab antara peserta dengan pemateri. Diskusi dilakukan supaya peserta lebih memahami tentang materi yang sudah disampaikan. Melalui diskusi, sosialisai tidak hanya sekedar memberikan materi saja akan tetapi dapat sharing pengalaman maupun permasalahan yang sedang dihadapi oleh mitra.

Pada pasca kegiatan dilakukan evaluasi. Evaluasi pada pelaksanaan kegiatan Pengabdian Kepada Masyarakat untuk kegiatan selanjutnya adalah sebagai berikut:

a. Kegiatan Pengabdian Kepada Masyarakat yang diadakan oleh Fakultas Ekonomi dan Bisnis ini berjalan dengan baik dan sudah sesuai dengan rencana awal

b. Memberikan pemahaman kepada para pemuda karangtaruna Banyuurip Surabaya mengenai Kepemimpinan (leadership)

c. Untuk kegiatan Pengabdian Kepada Masyarakat selanjutnya disarankan supaya tidak berhenti pada memberikan pemaparan materi saja, akan tetapi dengan membina atau melakukan pelatihan agar suapaya peserta lebih termotivasi untuk menjadi pemimpin (leader) sejak usia muda 
d. Dengan diadakannya kegiatan pengabdian kepada masyarakat ini agar supaya bisa memotivasi dan bisa menumbuhkan sikap dan karakteristik kepemimpinan bagi para pemuda karangtaruna Banyuurip Surabaya.

e. Memberikan materi dan sekaligus mengadakan pelatihan mengenai kepemimpinan

Sedangkan Luaran yang ingin di capai pada kegiatan pengabdian masyarakat adalah sebagai berikut:

a. $85 \%$ meningkatnya pemahaman tentang sikap dan karakteristik kepemimpinan (leadership) dalam berorganisasi bagi para peserta

b. $60 \%$ peserta termotivasi untuk turut aktif dalam kegiatan organisasi kepemudaan

c. $50 \%$ peserta Para pemuda mempunyai sikap dan jiwa leadership dalam mempertahankan organisasi kepemudaan

\section{DISKUSI}

Berdasarkan hasil dari kegiatan pengabdian kepada masyarakat mengenai bagaimana cara membangun jiwa wirausaha kreatif (creativepreneur) kepada para pemuda karang taruna Banyu Urip, Surabaya yang dilaksanakan pada tanggal 02 Agustus 2020 ini berjalan dengan baik dan lancar. Para pemateri memberikan arahan dan sosialisasi mengenai kepemimpinan (leader) bagi para pemuda karangtaruna Banyu Urip agar mereka aktif dalam berorganisasi dalam mengembangkan jiwa kepemimpinan mereka.

Pada era saat ini, perilaku mengenai kepemimpinan menjadi hal yang perlu diimplementasikan pula kepada para karangtaruna Banyuurip agar tercapainya tujuan bersama dengan diadakannya peningkatan kesadaran mengenai kepemimpinan untuk menciptakan organisasi yang efektif bagi para pemuda karangtaruna. Hal ini guna bisa memberikan solusi bagi masyarakat dan juga menjadi perubahan baru untuk generasi selanjutnya. Kegiatan pengabdian masyarakat yang dilakukan oleh Fakultas Ekonomi dan Bisnis ini di sambut baik oleh peserta dan mereka juga meminta supaya kegiatan pengabdian masyarakat ini didakan secara berkelanjutan dengan melalui pelatihan sehingga para peserta dapat merasakan manfaatnya.

Rencana tindak lanjut berikutnya dari kegiatan pengabdian masyarakat ini adalah bimbingan yang dilakukan dengan cara mengadakan pelatihan kepemimpinan (leadership) secara langsung dan berkala. Hal ini dimaksudkan agar masyarakat dapat belajar menjadi seorang pemimpin yang baik dan bijaksana dalam berorganisasi atau pemimpin bagi dirinya sendiri. Setelah adanya pelatihan, akan diadakan pengawasan dan implementasi kegiatan baru yang ada di organisasi kepemudaan karang taruna Banyu Urip, Surabaya.

Hal ini dilakukan untuk melihat perkembangan seputar usaha kreatif yang sudah berjalan secara bertahap agar nantinya dapat diambil pelajaran untuk kedepannya. Selain itu, hal ini bisa membantu untuk mencapai keberhasilan dari kegiatan pengabdian masyarakat dan bisa menjadi evaluasi untuk mengadakan kembali kegiatan pengabdian masyarakat yang bertema kepemimpinan (leadership) atau cara meningkatkan sikap dan karakteristik kepemimpinan dalam berorganisasi bagi para pemuda karang taruna Banyu Urip, Surabaya. Kegiatan pengabdian kepada masyarakat ini diusahakan untuk diadakan setiap tahun, agar banyak masyarakat maupun para pemuda yang melahirkan pemimpinpemimpin baru yang hebat dan mampu membawa perubahan yang baik secara universal.

\section{KESIMPULAN}

Berdasarkan kegiatan yang telah dilaksanakan oleh tim pengabdian kepada masyarakat yang dilakukan kepada para pemuda karang taruna Banyu urip, Surabaya dapat disimpulkan bahwa pertama, kegiatan pengabdian kepada masyarakat yang mempunyai tema cara meningkatkan sikap dan karakteristik kepemimpinan (leadership)dalam berorganisasi bagi para pemuda karang taruna Banyu Urip, Surabaya berjalan dengan baik dan sesuai dengan target.

Kedua, kegiatan pengabdian kepada masyarakat ini berisi tentang pemapamaran materi oleh tim pengabdian masyarakat dalan dilanjutkan tanya jawab dan diskusi oleh peserta kepada pemateri, sehingga tidak hanya berbagi ilmu saja akan tetapi juga berbagi pengalaman mengenai kepemimpinan 
dan juga organisasi. Ketiga, dengan adanya kegiatan pengabdian masyarakat ini para peserta berantusias dan tertarik untuk turut aktif dan berkontribusi dalam organisasi dengan membuat ide kegiatan baru yang positif dan berharap agar kegiatan pengabdian masyarakat ini bisa ditindaklanjuti melalui pelatihan mengenai kepemimpinan. Adapun saran yang dapat disampaikan untuk peningkatan kegiatan selanjutnya adalah sebagai berikut:

1. Kegiatan pengabdian kepada masyarakat ini perlu diadakan lagi secara bertahap guna untuk menindaklanjuti kegiatan ini supaya tidak hanya sampai pada pemahaman materi saja akan tetapi diadakan dengan pelatihan mengenai kepemimpinan setiap tahun.

2. Kegiatan pengabdian kepada masyarakat ini untuk kedepannya bisa melibatkan banyak peserta lagi dari kalangan masyarakat dan anak muda agar mereka termotivasi untuk menjadi pemimpin yang bertanggungjawab dan juga memeberikan perubahan bagi para anak muda lainnya.

\section{PENGAKUAN}

Alhamdulillah, puji syukur kami panjatkan kehadirat Allah SWT atas Karunia-Nya, penyusunan laporan kegiatan pengabdian masyarakat dengan judul "Cara Meningkatkan Sikap dan Karkteristik Kepemimpinan (Leadership) dalam Berorganisasi Bagi Para Pemuda Karang Taruna Banyu Urip, Surabaya" ini dapat terselesaikan. Laporan kegiatan pengabdian masyarakat ini berisikan mengenai hasil kegiatan sosialisasi dosen dan mahasiswa mengenai sikap kepemimpinan bagi para pemuda karang taruna Banyu Urip, Surabaya. Kegiatan ini dilakukan dengan tujuan meningkatkan sikap dan karakteristik kepemimpinan dalam berorganisasi bagi para pemuda Banyu Urip, Surabaya. Dengan terselesaikannya laporan kegiatan pengabdian masyarakat ini, perkenankan saya mengucapkan terima kasih yang sebesar-besarnya kepada:

1. Prof. Dr. Ir. Achmad Jazidie, M.Eng selaku Rektor Universitas Nahdlatul Ulama Surabaya.

2. Dr. Istas Pratomo, S.T., M.T selaku Ketua Lembaga Penelitian dan Pengabdian Masyarakat Universitas Nahdlatul Ulama Surabaya.

3. Dr. Mohamad Yusak Anshori, M.M Dekan Fakultas Ekonomi dan Bisnis Universitas Nahdlatul Ulama Surabaya.

4. Riyan Sisiawan Putra, S.E., M.SM selaku Ketua Program Studi S1 Manajemen Universitas Nahdltul Ulama Surabaya.

5. Moch Imam Suyuti selaku Ketua RT.02 Banyu Urip Jaya dan para pemuda karang taruna Banyu Urip, Surabaya atas bantuannya selama kegiatan berlangsung.

6. Para anggota pelaksana pengabdian masyarakat yang terlibat dalam pelaksanaan pengabdian masyarakat.

Demikian, semoga laporan ini dapat memberi manfaat bagi diri saya sendiri, dan untuk pengembangan penelitian bidang kesehatan masyarakat maupun semua pihak yang menggunakan.

\section{DAFTAR PUSTAKA}

Putra, R. S. 2013. Pengaruh Budaya Perusahaan Terhadap Prestasi Kerja Karyawan PT Pembangkitan Jawa-Bali Surabaya Unit Pelayanan Pemeliharaan. Journal Vol.15 No.2 (131-140)

Robbins, Stephen P. Perilaku Organisasi. Jakarta : Indeks. . (2003)

Slater, Robert. Jack Welch and The GE Way : Wawasan Manajemen dan Rahasia Kepemimpinan CEO Legendaris (Terjemah oleh Fandy Tjiptono). Edisi I. Yogyakarta : ANDI (2001)

Stoner, James A.F., R. Edward Freeman, dan Daniel R. Gilbert Jr. Manajemen, Jilid II. Jakarta : Prenhallindo. (1996)

Suranta, S. Dampak Motivasi Karyawan Pada Hubungan Antara Gaya Kepemimpinan Dengan Kinerja Karyawan Perusahaan Bisnis. Jurnal Empirika (2002) 15 (2): 116-138. 
Wijoyo, H., \& Haudi, H. (2021, January). PENYULUHAN TEKNIK PEMASARAN KERUPUK RASA JENGKOL "DONG DONG SNACK" PEKANBARU. In PROSIDING SENANTIAS: Seminar Nasional Hasil Penelitian dan Pengabdian kepada Masyarakat (Vol. 1, No. 1, pp. 643-650).

Wijoyo, H. (2020). Socialization Of The Accreditation Asessment System (SISPENA) Of The National Accreditation Board For Early Childhood Education (PAUD) And Non Formal Education (PNF) In Bengkalis, Riau Province. Jurnal Humanities Pengabdian Kepada Masyarakat, 1(1), 103-111.

Wijoyo, H., Haudi, H., Ariyanto, A., Sunarsi, D., \& Akbar, M. F. (2020). Pelatihan Pembuatan Konten Digital Marketing Dalam Meningkatkan Kompetensi Mahasiswa (Pengabdian Kepada Masyarakat Kerjasama Antar Kampus). IKRA-ITH ABDIMAS, 3(3), 169-175.

Wijoyo, H. (2020). Sosialiasi Sistem Penilaian Akreditasi (SisPenA) Badan Akreditasi Nasional Pendidikan Anak Usia Dini (PAUD) dan Pendidikan Non Formal (PNF) di Kecamatan Bantan, Kabupaten Bengkalis, Propinsi Riau. ARBITRASE: Journal of Economics and Accounting, 1(1), 7-10. 